\section{A POLÍTICA ESPORTIVA BRASILEIRA NOS GOVERNOS DO PARTIDO DOS TRABALHADORES - PT (2003-2016) ${ }^{1}$}

\section{BRAZILIAN SPORTS POLICY IN THE GOVERNMENTS OF THE PARTIDO DOS TRABALHADORES - PT (2003-2016)}

\section{Nadson Santana Reis ${ }^{2, *}$ / Fernando Mascarenhas ${ }^{3}$ / Marlon Messias Santana $\mathrm{Cruz}^{4}$ /} Ana Gabriela Alves Medeiros 5

\begin{abstract}
RESUMO
$\mathrm{O}$ artigo apresenta e analisa os principais fundamentos da política esportiva adotada pelos governos do Partido dos Trabalhadores - PT, entre os anos de 2003 a 2016 Para tanto, por meio de uma revisão crítica da literatura e, de maneira complementar, de pesquisa documental, o trabalho desenvolve uma análise [e retrospectiva] histórica das principais características do setor esportivo brasileiro, bem como analisa as ações desses governos na condução das políticas afetas ao esporte até o ano de 2016, considerando, para isso, a criação do Ministério do Esporte, a realização das Conferências Nacionais de Esporte e a inserção do país na rota dos megaeventos esportivos. As considerações indicam que ocorreram, nesse período, mudanças importantes na condução da política esportiva, sobretudo a partir da III Conferência Nacional de Esporte que, não obstante, adotou os megaeventos esportivos como o princípio organizador da agenda governamental - fato que expressa, em certa medida, as transformações orquestradas no próprio Partido dos Trabalhadores.
\end{abstract}

Palavras-chave: Partido dos Trabalhadores. Políticas Públicas. Esporte.

${ }^{1} \mathrm{O}$ artigo contou com apoio financeiro na forma de bolsa de estudos - concedida a seu primeiro autor - da Coordenação de Aperfeiçoamento de Pessoal de Nível Superior - CAPES.

${ }^{2}$ Departamento de Educação - Campus XII, Universidade do Estado da Bahia, Guanambi, Bahia - Brasil

${ }^{3}$ Faculdade de Educação Física - Universidade de Brasília, Brasília, Distrito Federal - Brasil.

${ }^{4}$ Departamento de Educação - Campus XII, Universidade do Estado da Bahia, Guanambi, Bahia - Brasil

${ }^{5}$ Departamento de Educação - Campus XII, Universidade do Estado da Bahia, Guanambi, Bahia - Brasil.

*E-mail para correspondência: nadsonsr@hotmail.com \begin{abstract}
This article presents and analyzes the main foundations of the sports policy adopted by the governments of the Partido dos Trabalhadores - PT (left party) between 2003 and 2016. Thus, through a critical review of the literature and, in a complementary way, of documentary research, this paper develops a historical [and retrospective] analysis of the main characteristics of the Brazilian sports sector, also analyzes the actions of these governments in the conduct of sports policies up to 2016, considering the creation of the Ministry of Sports, the holding of the National Sports Conferences and the insertion of the country in the route of mega sports events. The considerations indicate that during this period there were important changes in the conduct of sports policy, especially since the III National Sports Conference, which nevertheless adopted mega sports events as the organizing principle of the governmental agenda - a fact that expresses, to some extent, the transformations in the Partido dos Trabalhadores itself.
\end{abstract}

Keywords: Partido dos Trabalhadores. Public Policies. Sport.

Submetido em: 20 de jun. 2018

Aceito em: 21 de nov. 2018

\section{INTRODUÇÃO}

A história do esporte no Brasil - como objeto de política pública - supõe pouca atenção do Estado no tocante à organização das ações voltadas ao atendimento das necessidades e demandas do conjunto da sociedade. Tal questão tem relação com a formatação de uma gestão das prioridades sociais e, também, em função do papel mobilizador de cada setor (a sociedade se organiza/mobiliza em torno de lutas por políticas salariais, saúde, educação e outros direitos sociais e menos em função de espaços, equipamentos e políticas de esporte e lazer) (LINHALES, 1996). Apesar disso, mesmo fora das prioridades, o esporte, conforme Bracht (2005), não passou ileso da atenção e intervenção do Estado brasileiro. Intervenção está que, guardada as devidas excepcionalidades, foi marcada por ações tutelares, permeadas por estruturas corporativas, herméticas, autoritárias, corruptas, clientelistas e centralizadoras (MANHÃES, 2002).

Rev. ComCiência - dez. 2018, vol. 3, no. 3, p. 77-89 / doi: 10.36112/issn2595-1890.v3i1.p77-89 
com Ciência

Uma revista multidisciplinar
A política esportiva brasileira nos governos do partido dos trabalhadores - PT (2003-2016)
Contudo, no fosso aberto pela luta dos brasileiros pela redemocratização do país, na década de 1980, o debate sobre os direitos sociais incorporou $\mathrm{o}$ esporte e o lazer que, não obstante, foram incluídos no novo pacto social representado pela Constituição Cidadã de 1988 que, inclusive, responsabilizou o Estado no provento dos direitos sociais.

A década de 1990, entretanto, marcada pela crise fiscal, pelas medidas de austeridade e, sobretudo, pelo desinvestimento público no setor de serviços em função da agenda neoliberal e da redução do Estado brasileiro nas questões sociais representou um duro golpe à tradução dos direitos sociais em políticas públicas afinadas com a justiça e equidade social como sinalizava o novo texto constitucional.

Contudo, a transição política de 2003 gerou, no conjunto da população brasileira, uma grande expectativa de mudança. No caso das políticas de esporte, o minoritário setor progressista da Educação Física e das Ciências do Esporte esperava um redirecionamento nos rumos e nas diretrizes das políticas esportivas. Fato que tinha relação com a chegada, pela primeira vez, de um partido político vinculado às classes trabalhadoras à estrutura organizativa governamental brasileira, bem como pela criação de um órgão responsável pela organização, elaboração e gestão de políticas públicas de esporte - o Ministério do Esporte (ATHAYDE, MASCARENHAS, SAVADOR, 2015).

Nessa direção, compreender crítica e cientificamente o que significou a agenda e a política esportiva desenvolvida pelos Governos do Partido dos Trabalhadores constitui uma tarefa importante para a defesa do esporte enquanto direito social, produto cultural e bem imaterial da humanidade que, por isso, precisa se constituir como objeto de políticas afinadas com a luta pela ampliação e consolidação desse direito. Ademais, implica no enriquecimento do debate acadêmicocientífico que tem potencial para contestar o risco renovado de instrumentalização do esporte no país.

Por isso, o intento deste artigo é apanhar, de forma panorâmica, o quadro desenhado pelas políticas esportivas desenvolvidas, no Brasil, entre os anos de 2003 e 2016, no âmbito dos Governos do Partido dos Trabalhadores. Desse modo, busca apontar as características mais gerais e mais pertinentes à compreensão do esporte como objeto de política pública nesse contexto.

Por isso, o trabalho em tela, de natureza qualitativa, resulta de uma pesquisa bibliográfica e documental que busca apanhar/analisar a agenda governamental implementada pelos governos do Partido dos Trabalhadores (2003-2016). Para tanto, procedeu-se conforme sugere Lima e Mioto (2007) - à seleção da literatura com vistas a responder ao objetivo almejado, a caracterização e consequente identificação das contribuições e/ou informações úteis e pertinentes ao estudo e, por fim, ao exame de alguns documentos com a finalidade de apreender os fundamentos lógico-conceituais que balizaram a política esportiva brasileira.

\section{A herança esportiva legada aos Go- vernos do Partido dos Trabalhado- res ${ }^{6}$.}

${ }^{6}$ Nesse texto a expressão 'governo do Partido dos Trabalhadores (PT)' refere-se ao período em que Partido dos Trabalhadores e sua base aliada esteve à frente do Governo Federal brasileiro: governos Lula e Dilma (2003-2016).
Tomando as políticas esportivas como produtos de condições históricas determinadas que se desenvolvem por negação, incorporação, involução e saltos de qualidade passa-se, então, a uma rápida e abreviada caracterização do setor esportivo brasileiro herdada pelo Partido dos Trabalhadores (PT), a fim de demonstrar sua base política e ideológica, bem como seu perfil nitidamente conservador - aspectos essenciais à apropriação do conjunto de ações empreendidas na sequência de 2003.

A chegada do esporte no Brasil, notadamente do futebol, sugere uma ação de transplante cultural orquestrada pela elite ociosa do país. Em seu processo de consolidação, a igreja católica e as forças armadas - instituições de caráter majoritariamente conservador e autoritário - ancoraram as atividades esportivas, condicionandoas segundo seus interesses. Tais fatos levaram Ouriques (2014) a afirmar que o desenvolvimento do esporte brasileiro supõem características colonialistas e reacionárias.

No âmago deste processo, a presença e intervenção do Estado, no setor, variaram segundo os interesses e anseios que mobilizaram os distintos projetos de nação ao longo da história brasileira. Desse modo, a primeira fase, empreendida pelo Estado Novo, foi marcada por forte tendência autoritária - caracterizada, majoritariamente, pelo disciplinamento e organização do campo esportivo.

$\mathrm{Na}$ Ditadura Militar, o anseio por conferir legitimidade aos governos militares e elevar o Brasil à condição de potência olímpica balizou a intervenção do Estado no setor.

Em 1988, por ocasião da Constituição Federal, em meio à reto- 
mada da democracia, o esporte foi reconhecido como um direito de cada um - muito embora não figurasse como uma das demanda/reclame da classe trabalhadora do país. Ainda para o texto constitucional, a dimensão educacional esportiva deveria receber prioridades na dispensa dos gastos públicos (MANHÃES, 2002).

Entretanto, conforme Ouriques (2014, p. 16) poucos foram os projetos que - na sequência de 1988 assumiram a bandeira de sua democratização junto à população nacional, de maneira que o esporte "[...] seguiu cumprindo sua função no plano da alienação, da mercantilização e da propaganda do Estado, tanto nacional como internacionalmente".

No governo Collor, buscando redimensionar o esporte nacional, vários esforços foram somados no sentido de atualizar/modernizar a legislação esportiva, o que se materializou na elaboração da Lei Zico (Lei no . 8.672, de 06 de julho de 1993). Uma lei que tentou vincular o esporte à nova situação do país rumo à democracia e aos novos interesses liberais do mercado internacional, além de procurar romper com os anacronismos autoritários que caracterizavam o campo esportivo.

Ainda de acordo com Ouriques (2014), a Lei Zico foi fundamental para que, no âmbito do governo Fernando Henrique Cardoso (FHC), se instalasse reformas afinadas com um projeto modernizador neoliberal e conservador - cujo intuito era abrir o mercado brasileiro aos interesses internacionais. Desse modo, embora nos anos que compreende este governo o esporte não goze de prestígio, merece destaque a edição da Lei Pelé (Lei no 9.615, de 24 de março de 1998); a criação do Ministério do Esporte e
Turismo (MET); e a instalação e realização da Comissão Parlamentar de Inquérito (CPI) do Futebol [no Senado Federal] e do contrato CBF-Nike [na Câmara Federal].

A Lei Pelé, por exemplo, enfatizou o direito ao esporte como parte da cidadania, principalmente, ao destacar as dimensões do esporte participativo e educacional. Todavia sua ênfase recaiu no interesse pela abertura do mercado para o futebol - considerado a melhor mercadoria do esporte nacional.

De maneira coerente, conforme Manhães (2002), o texto da referida lei tornou facultativa a filiação das entidades de prática às entidades de administração, passando a permitir a criação de ligas nacionais e regionais. Tornou, ainda, o esporte praticado por atletas profissionais privativo de entidade de prática (clubes) - segundo a legislação comercial - em empresas.

Linhales (1996) situa esse processo de mudança (que compreende a Lei Zico e a Lei Pelé) no seio do confronto entre os interesses liberalizantes - que buscavam autonomia de mercado para o esporte - e os interesses conservadores - que entendiam essa liberalização como uma ameaça ao poder constituído oligarquicamente. Em sua análise, o embate entre liberalizantes e conservadores foi responsável pelo surgimento da autonomia e da pluralidade como elementos de mudança.

Manhães (2002) afirma, ainda, que no bojo e cristalização desse modelo de organização esportiva, proposto pela Lei Pelé, desenvolveu-se oligarquias dirigentes resistentes às mudanças na constituição das entidades dos esportes praticados por profissionais. Paralelo a isso, o crescimento das atividades de negócios e estruturação de competições e espetáculos como atividade econômica sistematizada criou um quadro de dano administrativo marcado por indícios de corrupção. Neste cenário, em 1998, a Câmara dos Deputados abriu uma CPI para investigar o contrato 'CBF-Nike' e, no Senado Federal, o futebol de maneira geral.

Muito embora as denúncias levantadas pela CPI da Câmara tenham sido significativas, seu relatório não chegou a ser votado, fruto de medidas protelatórias e atentatórias ao decoro empreendidas pela Confederação Brasileira de Futebol - CBF. Contudo, no Senado, em meio à reprovação da opinião pública do desfecho da CPI da Câmara, o relatório foi aprovado por unanimidade. Tal documento recomendava o indiciamento dos envolvidos e medidas administrativas e legislativas transformadas (MANHÃES, 2002).

Diante disso, em 2003, FHC ao passar o 'bastão' a Lula o entregou, mais do que um campo esportivo conservador e reacionário, um setor ressentido, desintegrado, comprovadamente corrupto e patrimonialista, bem como sem credibilidade diante da opinião pública brasileira. Cabia, então, ao novo presidente reintegrá-lo, reorganizá-lo, colocá-lo nos trilhos... Muito embora, ao fim e ao cabo, a expectativa fosse exponencialmente maior..

\section{Aspectos da política esportiva nos governos do Partido dos} Trabalhadores.

$\mathrm{O}$ anseio pela democratização da cultura corporal - na qual o esporte se insere - converteu-se, de um lado, em "desejo de alguns poucos setores da sociedade civil" - notadamente dos grupos de pesquisa que se dedicavam a 
entendê-la como uma dimensão importante da experiência humana e, portanto, direito inalienável a todos os cidadãos - e, de outro, em "compromisso da esquerda" - traduzido nas propostas do Partido dos Trabalhadores para as políticas públicas de esportes, já em 1989.

Em 1989, por ocasião da entrevista dos presidenciáveis ao 'Jornal dos Sports'7, Luiz Inácio Lula da Silva, candidato pelo PT, destacou a importância de consolidar uma política progressista de esporte no Brasil. Para o então candidato, as entidades de administração esportiva preservavam características organizativas eminentemente corporativas e autoritárias aspectos que justificavam a necessidade de estabelecer novos referenciais para a gestão esportiva no país. Para Lula

[...] a educação física como um fenômeno cultural e como tal, produto da ação humana, dotado de historicidade, de saber, de história e conhecimento - conhecimento esse que devem ser democratizados de forma a se poder constituir uma cultura corporal e esportiva na perspectiva da construção do homem e da sociedade socialista (SILVA, 1989, p. 130).

Tal discurso é emblemático do teor progressista dado ao esporte, uma vez que o referido entrevistado impõe relevo à importância da democratização da cultura corporal e esportiva na construção do homem e da sociedade socialista. Ademais, o 'Jornal dos Sports' o questionou sobre a necessidade de criação de um 'Centro de Capacitação Física' integrando ensino,

${ }^{7} \mathrm{O}$ conteúdo das entrevistas com todos os presidenciáveis (Collor, Afiff Domingues, Maluf, Mário Covas e Luiz Inácio Lula da Silva) foram publicadas na Revista Motrivivência, em junho de 1989. pesquisa e extensão para alavancar o esporte no país e as condições de saúde da população. Nessa direção, Lula reconheceu a necessidade de uma visão mais complexa em torno da saúde - tomando-a como resultante das condições de vida da população, viabilizada pelo acesso, também, a bens sociais e culturais (entre os quais situam o esporte e lazer).

Ainda segundo o candidato, a participação do país nos Jogos Olímpicos não poderia prescindir de algumas conquistas, muito embora para a atuação brasileira fosse fundamental uma lição de participação e de espírito esportivo e lúdico.

Sobre as políticas esportivas, Luiz Inácio Lula da Silva foi categórico ao afirmar a necessidade de uma política esportiva que se constituísse como parte integrante de uma política de governo, as quais (na sua fala) não se constroem a partir da soma de variadas políticas setoriais, mas na interlocução delas numa mesma totalidade. Nessa linha, concluiu que: ao governo compete destinar a arrecadação fiscal na tentativa de atender ao conjunto das "[...] necessidades sociais indicativas da qualidade de vida de um povo [...]" (SILVA, 1989, p.131).

Tais argumentos elucidam a perspectiva apresentada pelo Partido dos Trabalhadores e por Lula no ano de 1989. Trata-se de elementos importantes e fundamentais à compreensão do próprio PT e das atuais políticas de esporte, mesmo porque, permitem identificar incoerências e imprecisões, além de descompassos históricos essenciais - o que corrobora por sugestionar um processo de mudanças engendradas no âmbito do Partido dos Trabalhadores - traço de importância vital à compreensão das políticas produzidas na sequência de 2003.

A análise/avaliação de Silva, Silveira e Ávila (2007, p. 157) a despeito do projeto do PT para o setor, em $1989^{8}$, à luz das políticas públicas de esporte implementadas a partir de 2003 implica atenção a três pontos fundamentais (com os quais se tem acordo):

a) os descaminhos das políticas públicas traçadas naquela época sob a 'construção do homem e da sociedade socialista' e a opção pelos preceitos, lógica e rumos neoliberais das políticas sociais hoje instauradas, a partir das 'alianças' políticas firmadas com os setores mais conservadores da burguesia política brasileira e com as instituições gestoras do capital internacional [...];

b) o negligenciamento ao conceito positivo de saúde coletiva, implícita nas entrelinhas de sua fala, ao articular a relação positiva entre políticas esportivas e políticas sociais (saúde, educação, trabalho e lazer) [...]; c) a substituição do conceito de 'democratização' do esporte, ou saberes da cultura corporal nos pressupostos políticos-pedagógicos das políticas esportivas, pelos conceitos balizadores da ideologia da inclusão social e cidadania, presente nos documentos que fundamentam as ações, projetos e programas das políticas esportivas atuais.

Há, também, a necessidade de destacar os descompassos entre a perspectiva apresentada por Lula para a participação do Brasil em eventos esportivos - a qual privilegiava uma lição de participação e espírito esportivo/lúdico, mesclada com algumas conquistas - e a prevalência (em seus governos e, também, nos da presidente Dilma Rousseff) de uma agenda esportiva subjugada pelo interesse de projetar o país tanto no esporte, como na

${ }^{8}$ Cujo conteúdo está expresso na entrevista de Lula ao 'Jornal dos Sports'.

Rev. ComCiência - dez. 2018, vol. 3, no. 3, p. 77-89/doi: 10.36112/issn2595-1890.v3i1.p77-89 
política e na economia (MASCARENHAS et al. 2012).

Entender essa guinada implica, conforme os autores, reconstituir a trajetória do Partido dos Trabalhadores, o que não constitui objetivo deste espaço temático. Todavia cabe demarcar, de forma abreviada, a transição de um partido de esquerda "contra a ordem" que - em um dado período - foi intitulado o "maior partido de esquerda do mundo", para um partido "dentro da ordem".

Segundo Coutinho (2006), o PT, ao menos no início, enquanto uma organização política surgida a partir dos movimentos sociais, da organização sindical, das comunidades eclesiásticas de base, dos setores de oposição ao regime militar e daqueles que resistiam à implantação de um projeto neoliberal no Brasil com estratégias socialistas (ainda que não muito claras) foi capaz de manter questões da 'grande política' ${ }^{9}$ no debate político brasileiro. Para o autor, a ofensiva neoliberal encontrou no PT e nos movimentos a ele direta ou indiretamente ligados (Central Única dos Trabalhadores - CUT; Movimento Sem-Terra MST; Comissão Pastoral da Terra CPT; etc.) uma grande resistência.

Ressalva-se que toda essa base de sustentação do PT foi, ao longo dos anos 1990, afetada pelo conjunto de transformações orquestradas no mundo do trabalho, sobremaneira o processo de reestruturação produtiva e a precarização das condições de trabalho que

\footnotetext{
${ }^{9} \mathrm{~A}$ grande política compreende questões ligadas à fundação de novos Estados, à luta pela destruição, pela defesa, pela conservação de determinadas estruturas orgânicas econômico-sociais. A pequena política compreende as questões parciais e cotidianas que se apresentam no interior de uma estrutura já estabelecida em decorrência de lutas pela predominância entre as diversas frações de uma mesma classe política (GRAMSCI apud COUTI-
} NHO, 2006, p. 98). instauraram, em seu seio, processos de fragmentação e enfraquecimento (MARINGONI apud ATHAYDE, 2014).

Nessa direção, a chegada do PT ao governo federal, segundo as análises de Coutinho (2006), passou longe de minar a hegemonia neoliberal. Para o autor, o 'transformismo' 10 que afetou o PT e seu governo foi, também, responsável pelo enfraquecimento da esquerda na correlação de forças que vigorara depois da transição - correlação esta que possibilitou a conquista de uma Constituição na qual estavam inscritos vários direitos sociais e que impediu, nos anos seguintes, a consolidação de um modelo neoliberal de Estado.

Na leitura de Athayde (2014), a ascensão do PT à presidência demandou do partido e do próprio expresidente Lula um conjunto de 'ajustes' - os quais, também, caracterizam o 'transformismo' já mencionado que, dentro de ampla gama de objetivos, tinham o intuito de conceder à campanha presidencial uma aparência mais amena, arrefecendo as posições reativas advindas de setores conservadores, notadamente aqueles ligados às frações de classes vinculadas à indústria nacional e ao capital financeiro. Nessa direção, merece destaque: a) a ampliação da coligação partidária, alinhando-se a partidos de centrodireita; b) o anúncio para o cargo de vice-presidente de personagem ligado ao setor industrial, a fim de tranquili-

\footnotetext{
${ }^{10}$ Fenômeno político caracterizado pela cooptação de lideranças políticas e culturais das classes subalternas (COUTINHO, 2006). Sua finalidade é excluir tais lideranças do efetivo protagonismo nos processos de transformação social. De maneira que implic a, numa visão gramsciana, na obtenção de consenso estratégico pelo bloco no poder, mediante a incorporação passiva de personalidades opositoras e/ou de grupos radicais que se tornam moderados (ATHAYDE, 2014).
}

zar os representantes da indústria nacional; e, c) a divulgação da 'Carta ao Povo Brasileiro ${ }^{11}$. Nesse sentido, a passagem a seguir é ilustrativa:

\begin{abstract}
[...] ao contrário da potência criadora das lutas sociais da década de 1980, o cenário era de estancamento das forças sociais do trabalho, embaralhadas em meio a tanta desertificação social. A eleição que levou Lula ao poder foi, por isso, uma vitória política tardia. Nem o PT, nem mesmo o país eram mais os mesmos. O segundo estava desertificado enquanto o primeiro havia se desvertebrado (ANTUNES, 2005, p. $165)$.
\end{abstract}

Malgrado todo esse processo, a chegada de Lula à Presidência da República foi marcada pelo compromisso de mudanças. O que gerou expectativas de alterações significativas, inclusive no campo esportivo, sobremaneira no estabelecimento de políticas públicas capazes de assegurar o acesso ao esporte como direito social e, portanto, responsabilidade do Estado (CASTELLANI FILHO, 2008).

Todavia, conforme Athayde (2014), o conjunto das transformações orquestradas no âmbito do PT se consolidou e se constituiu numa referência para o modus operandi do governo, mesmo após a conquista da presidência e do arrefecimento da vulnerabilidade econômica. $\mathrm{O}$ que significa dizer que o conjunto das pautas de cunho

\footnotetext{
${ }^{11}$ Por meio desse documento Lula se comprometia a dar ênfase à questão econômica, a desenvolver uma gestão fiscal "responsável", a priorizar o "controle da inflação", a "respeitar os contratos" nacionais e internacionais, a promover a "produção" e incentivar as "exportações" em busca de ampliação do "mercado internacional". Para muitos atores e analistas a Carta representou, também, um "recado" para as tendências mais à esquerda, dentro e fora do PT, de que o governo Lula não realizaria transformações substanciais no modelo econômico (MESQUITA; OLIVEIRA; NERY, 2007).
} 
com Ciência

Uma revista multidisciplinar

A política esportiva brasileira nos governos do partido dos trabalhadores - PT (2003-2016)

progressista, bem como os anseios por mudanças foram submetidos e/ou relegados aos determinantes macroeconômicos e à manutenção da governabilidade.

Desse modo, no modelo de desenvolvimento adotado por Lula e endossado por Dilma Rousseff, coube ao Estado apoiar as grandes empresas nacionais a fim de garantir a competitividade necessária no mercado mundial.

Nesse sentido, não houve ruptura, mas uma aliança com a burguesia e o fortalecimento do capital nacional privado - um dos principais traços definidores do bloco de poder e modelo de desenvolvimento conduzido e organizado pelo governo (BOITO Jr., 2005).

É no âmago e sedimentação desse processo que as políticas de esporte foram produzidas. Para compreendê-las cabe, também, observar atentamente as iniciativas do novo presidente para o setor.

\section{O Ministério do esporte}

Uma das mais importantes ações políticas, no campo do esporte, foi a criação de um Ministério específico. $\mathrm{O}$ que representou a tentativa de organizar uma estrutura administrativa para o esporte no país, sinalizando maior participação do Estado nas questões concernentes à atividade esportiva. Sua justificativa circunscrevia, conforme o governo, a necessidade de viabilizar a melhoria da gestão administrativa e financeira, legitimada pela urgência " [...] de uma política com programas e ações contínuas e articuladas, de abrangência nacional, apta a relacionar o público e o privado no desenvolvimento do setor" (ATHAYDE, 2014, p. 268).
Entretanto, Athayde (2014) alerta [ainda] que a criação de novas estruturas ministeriais (como a do Esporte) refletiu a necessidade do governo em acomodar os apoios da coalizão partidária vitoriosa.

Assim, diante do imperativo de acomodar os aliados, Lula estabeleceu um arranjo institucional que contou com a cessão do Ministério do Esporte ao Partido Comunista do Brasil (PC do B). Matias (2013) observa que o referido partido esperava do governo recém-eleito um posto que tivesse maior visibilidade, de modo que o conjunto das lideranças ligadas ao PC do B o aceitou a contragosto, agravado pelo fato de que teriam de dividir o Ministério com o setorial do PT ligado ao esporte.

Mas, afinal, qual seria o papel a ser desempenhado pelo novo Ministério no campo esportivo? Nessa direção, buscando definir suas competências, o Decreto $n^{\circ}$. 4.668, de 09 de Abril de 2003, estabeleceu como responsabilidade da nova pasta:

a) A política nacional de desenvolvimento da prática dos esportes;

b) $\mathrm{O}$ intercâmbio com organismos públicos e privados, nacionais, internacionais e estrangeiros, voltados à promoção do esporte;

c) $\mathrm{O}$ estímulo às iniciativas públicas e privadas de incentivo às atividades esportivas;

d) O planejamento, coordenação, supervisão e avaliação dos planos e programas de incentivo aos esportes e ações de democratização da prática esportiva e inclusão social por intermédio do esporte.
Para isso, a referida pasta foi dotada de uma estrutura organizativoadministrativa que agregou, inicialmente, órgãos de assistência direta e imediata ao ministro de Estado (Gabinete; Secretaria Executiva; e Consultoria Jurídica); órgãos específicos singulares (Secretaria de Esporte Educacional; Secretaria Nacional de Desenvolvimento de Esporte e Lazer; e Secretaria Nacional de Esporte de Alto Rendimento); além de órgão colegiado (Conselho Nacional do Esporte $\mathrm{CNE}$ ).

Já em 2005, por meio do documento chamado "Política Nacional de Esporte", o próprio Ministério do Esporte publicou uma série de metas e/ou objetivos que deveriam ser perseguidos pela pasta, a saber:

a) Democratizar e universalizar o acesso ao esporte e ao lazer, na perspectiva da melhoria da qualidade de vida da população brasileira;

b) Promover a construção e o fortalecimento da cidadania, assegurando o acesso às práticas esportivas e ao conhecimento científico-tecnológico a elas inerente;

c) Descentralizar a gestão das políticas públicas de esporte e de lazer;

d) Fomentar a prática do esporte de caráter educativo e participativo, para toda a população, além de fortalecer a identidade cultural esportiva a partir de políticas e ações integradas com outros segmentos;

e) Incentivar o desenvolvimento de talentos esportivos em potencial e aprimorar o desempenho de atletas e paratletas de rendimento, promovendo a de- 
mocratização dessa manifestação esportiva (BRASIL, 2005).

$\mathrm{O}$ atendimento a esse conjunto de metas/objetivos reclamou novos arranjos na recente estrutura organizativo-administrativa. Muito embora os aspectos conjunturais e as disputas internas tenham sido cruciais para uma série de mudanças orquestradas no âmbito do Ministério do Esporte, sobremaneira na sequência de 2007. Um dos exemplos mais emblemáticos foi criação de órgão específico para o futebol, dotando o Ministério de quatro secretarias: Secretaria Executiva; Secretaria Nacional de Esporte, Educação, Lazer e Inclusão Social; Secretaria Nacional de Futebol e Defesa dos Direitos do Torcedor; Secretaria Nacional de Esporte de Alto Rendimento e outros órgãos de gestão, como se pode observar no organograma a seguir (Figura 1).

As relações/tensões (disputa por hegemonia) travadas no seio dessa formatação técnico-administrativa, acrescidas pela pressão estabelecida pelas entidades da sociedade civil resultaram em ações/políticas/programas que portam as contradições que emergem e habitam tal estrutura ministerial.

$\mathrm{Na}$ análise de Mendes e Codato (2015), esse arranjo administrativo ${ }^{12}$

\footnotetext{
${ }^{12}$ Caracterizado por (1) estrutura institucional inadequada em termos de recursos humanos e impedimentos à participação de outros atores sociais além dos oficiais (parlamentares e membros do Ministério do Esporte) na política esportiva; (2) desarticulação entre as instituições públicas gerando redundâncias e conflitos de competência em função da má divisão de trabalho entre as agências burocráticas; e (3) planejamento inadequado constatado pela falta de organização de algumas instituições, pela falta de avaliação e de continuidade das políticas públicas ao longo do tempo (MENDES; CODATO, 2015, p. 564).
}

Figura 01: Estrutura e Organização do Ministério do Espor-

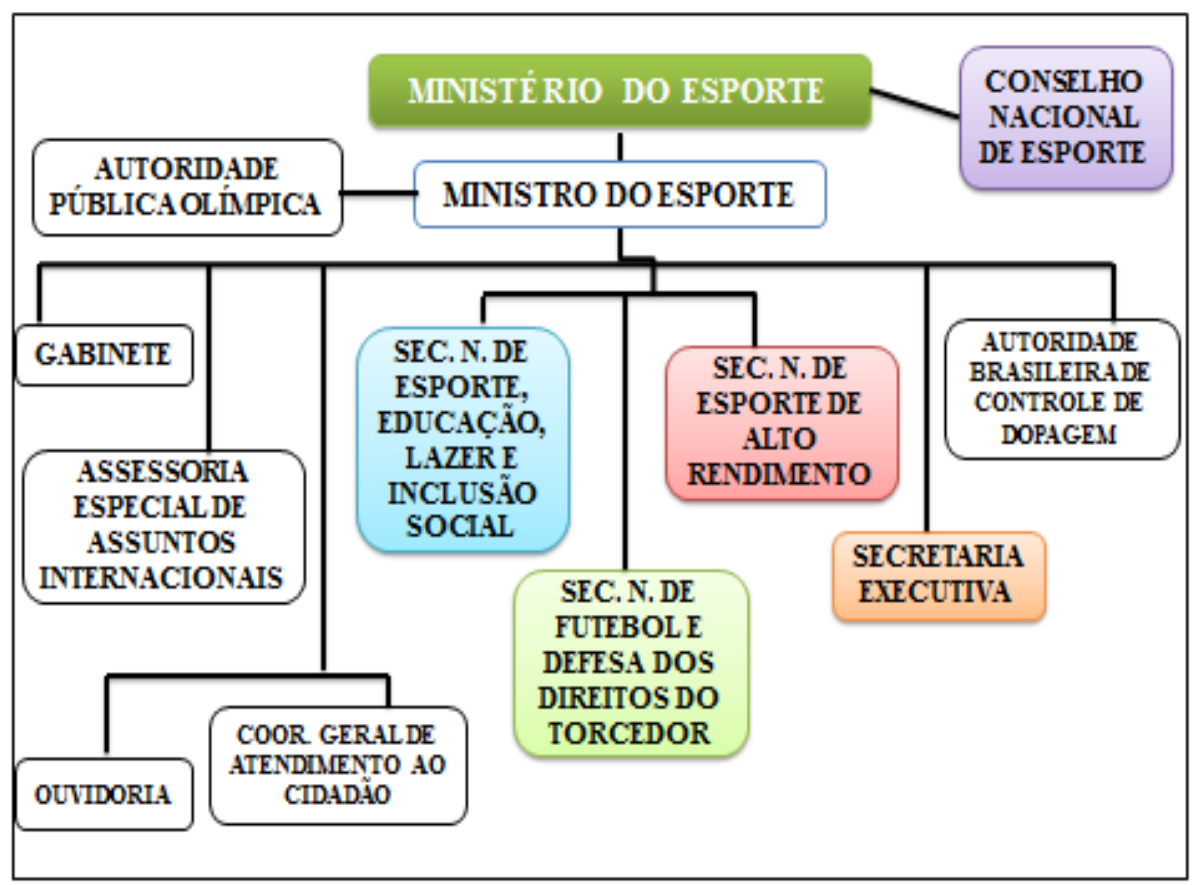

- incapaz de superar contradições e ambiguidades históricas - acaba por colocar grandes desafios à política esportiva brasileira. Desafios estes que incluem a formação de um "sistema" esportivo nacional e um investimento prioritário no esporte educacional.

Assim, embora o ministério tenha incorporado - inicialmente - um discurso de teor progressista - também verificado por Castelan (2011) - (cujo conteúdo pode, em parte, ser observado nas metas do próprio ME - apresentadas acima) os anseios populares, notadamente pela adoção de um modelo de gestão pautado em preceitos democráticos e de transparência, não foram viabilizados no conjunto da ação estatal (CASTELLANI FILHO, 2008; ATHAYDE, 2014).

$\mathrm{O}$ primeiro autor, por exemplo, foi enfático ao afirmar que os seis primeiros anos do Governo Lula foram marcados por um modelo híbrido de intervenção estatal, no qual o Estado intervinha, embora não na direção de restituição do sentido público da prática social esportiva, uma vez que alimentava a ideia do esporte como produto da economia brasileira, inscrito nos limites da mercadoria. Ganha relevo, então, a consideração de Mascarenhas et al. (2012, p. 30) segundo a qual "a chegada do PT ao Estado também não trouxe ruptura com o status quo da área, pois o pragmatismo impediu qualquer possibilidade de debate programático [...]”.

De acordo com Castellani Filho (2013), a busca por legitimidade no campo esportivo fez com que o Ministério desenvolvesse uma postura de submissão e subserviência voluntária às entidades de administração (Comitê Olímpico Brasileiro e Confederação Brasileira de Futebol), resultando no alinhamento das políticas para o setor aos interesses da fração conservadora do campo esportivo.

Nos termos de Matias (2013, p. 92), o anseio "[...] por legitimidade e visibilidade político-eleitoral fizeram 
com Ciência

Uma revista multidisciplinar
A política esportiva brasileira nos governos do partido dos trabalhadores - PT (2003-2016) os membros do PC do B se aproximar e sucumbir aos interesses dos atores do esporte-mercadoria-espetáculo" - elementos que, para Athayde (2014), traduzem um processo de aparelhamento e homogeneização da recente estrutura ministerial. Para este último, a consolidação das relações entre governo federal/entidades de administração esportiva/esporte-mercadoriaespetáculo se expressa pela negociação e formulação de uma série de dispositivos, tais como: o Estatuto de Defesa do Torcedor (EDT), em 2003; a criação do 'Bolsa Atleta', em 2004; a Lei de Incentivo ao Esporte (LEI); e a Timemania, em 2006. O ápice desta articulação/aliança se dá em 2007, com a realização dos Jogos Pan-americanos do Rio de Janeiro.

As Conferências Nacionais de Esporte: a opção pelo alto rendimento.

As três Conferências ${ }^{13}$ Nacionais de Esporte (CNE) - 2004, 2006, 2010 - se constituíram em espaços fundamentais para a formatação do conjunto de políticas esportivas que estavam em curso no país. Já que, por um lado, elas representaram uma novidade para o campo esportivo (pela primeira vez a sociedade civil organizada foi chamada a pensar uma política esportiva no país) e, por outro, inauguraram um mecanismo que viabilizava o debate em torno da necessidade de democratização das práticas esportivas e de controle social democrático $^{14}$.

\footnotetext{
${ }^{13}$ Cabe a ressalva de que no governo Lula as conferências foram tomadas como espaços deliberativos e de participação destinados a promover diretrizes para a formulação e o controle de políticas públicas em âmbito federal.

${ }^{14} \mathrm{O}$ controle social democrático supõe a participação da sociedade civil com a finalidade de promover a transparência na deliberação e visibilidade
}

A I CNE, de 2004, cujo tema foi 'Esporte, lazer e desenvolvimento humano' teve como objetivo '[...] democratizar a elaboração de Políticas na área de esporte e lazer, envolvendo e valorizando a participação de todos os segmentos da sociedade brasileira [...]" (BRASIL, 2009, p. 05). Metodologicamente a I CNE envolveu três etapas - municipal/regional, estadual e nacional - organizada em eixos temáticos, a saber: esporte de alto rendimento; esporte educacional; futebol; esporte, lazer e qualidade de vida; direito ao esporte e ao lazer; esporte, economia e negócios; esporte, administração e legislação; esporte e conhecimento (BRASIL, 2004).

O principal apontamento consubstanciado nas deliberações desta edição foi a formação da Política Nacional de Esporte, com ênfase na inclusão social e na democratização do esporte e lazer como direitos sociais (CASTELAN, 2011; FLAUSINO, 2013).

A II CNE, realizada em maio de 2006, com o tema 'Construindo o Sistema Nacional de Esporte e Lazer' preservou o modelo organizativo de sua primeira edição. Para Flausino (2013), os desdobramentos dos debates realizados nesta conferência, traduzido em documentos, mantiveram sintonia com o discurso presente na Política Nacional de Esporte (em decorrência da I CNE): foco no esporte como direito social, tendo a democratização e universalização do acesso ao esporte e lazer como premissa. Desse modo, Athayde (2014) argumenta que no âmbito da II CNE foi dado prossegui-

das ações, democratizando o sistema decisório; permitindo maior expressão e visibilidade das demandas sociais; viabilizando a defesa e alargamento de direitos. Nessa direção, os Conselhos tem grande envergadura como arenas de negociação e disputas (BEHRING; BOSCHETTI, 2008). mento aos apontamentos da edição anterior.

Entretanto, a III Conferência Nacional de Esporte, realizada em 2010, cujo tema foi 'Plano Decenal de Esporte e Lazer - 10 pontos em 10 anos para projetar o Brasil entre os 10 mais', teve como objetivo definir os rumos das políticas de esporte e lazer, consubstanciando-os num Plano Decenal, muito embora a pauta das duas últimas conferências apontasse para a construção de um Sistema Nacional de Esporte e Lazer.

Para Castelan (2011), Mascarenhas (2012), Flausino (2013), Matias (2013) e Athayde (2014), o conjunto das atividades da III CNE foi direcionado para os megaeventos esportivos priorizando e privilegiando o esporte de alto rendimento e esporte espetáculo. Para Flausino (2013) a participação popular serviu, neste espaço, apenas para legitimar os interesses do governo, da iniciativa privada e das entidades de administração esportiva. Em Matias (2013), por exemplo, essa terceira edição expressa o consenso obtido pelo bloco de poder (Estado, entidades de administração esportiva e mercado), para a qual os grandes eventos constituíram em princípio organizador. Não obstante, a fala do então ministro Orlando Silva é elucidativa:

A vitória do Rio de Janeiro como cidade sede para as Olimpíadas e Paraolimpíadas de 2016 concretiza os esforços do governo federal para colocar o país no centro dos grandes eventos esportivos mundiais. Um marco decisivo foi a realização, em 2007, no Rio, dos melhores Jogos Pan-americanos da história. Trouxemos a Copa de 2014 e agora as Olímpiadas 2016, um feito inédito. A conquista de sediar os maiores eventos esportivos do mundo se sustenta no paradigma dos legados que con-

Rev. ComCiência - dez. 2018, vol. 3, no. 3, p. 77-89/ doi: 10.36112/issn2595-1890.v3i1.p77-89 
tribui com o crescimento do Brasil, a transformação urbana das cidades e o desenvolvimento social sustentável por meio do esporte. [...] Esse conjunto de fatores torna a política do esporte estratégica para o desenvolvimento do país que pretende ser a quinta potência econômica em 2016 e, figurar entre as dez potências olímpicas do mundo (BRASIL, 2009, p. 07).

Nessa mesma direção, Athayde (2014, p. 285) analisando o processo de construção, materialização e desdobramentos da III CNE, brevemente apontados neste espaço, conclui que sua consumação foi uma "[...] prova inconteste da deliberação "pelo alto' 15 dos rumos da política de esporte nacional, deslegitimando o processo construído ao longo das conferências anteriores". Argumento confirmado por Mascarenhas (2012) ao afirmar que tal agenda governamental excluiu a participação popular e o controle democrático, uma vez que foi construída de forma verticalizada pelo Comitê Olímpico Brasileiro ( $\mathrm{COB}$ ) e representantes do governo, sem a participação da sociedade civil organizada.

\section{Os megaeventos esportivos como princípio norteador/organizador da agenda esportiva brasileira.}

A definição da agenda compreende um momento decisivo na formulação das políticas públicas, delimitando um objeto de intervenção estatal. Partindo dessa premissa, Mas-

${ }^{15}$ Coutinho (2006) identifica no processo de construção do Estado nacional brasileiro processos de transição que se dão 'pelo alto', numa referências ao conjunto de acordos e decisões tomadas pelas frações de classes dominantes, cujo objetivo é a exclusão da participação das massas populares. Trata-se, portanto, de acordos ou manobras pelo alto entre segmentos 'modernos' e 'arcaicos'. carenhas et al. (2012, p. 17), asseguram que as políticas públicas de esporte e lazer foram influenciadas pelo objetivo de projetar internacionalmente o país tanto no esporte, como na área política e econômica. "Por conseguinte, os megaeventos esportivos passaram a constituir o princípio organizador da agenda de esporte e lazer do país".

Almeida e Bracht (2013) também asseveram o poder normativo dos megaeventos esportivos ao reconhecer seu poder simbólico e econômico aspectos que estão relacionados a uma série de características do esporte de alto rendimento que lhes conferem grande apelo popular e adesão apaixonada.

Nesse escopo, o caso brasileiro é exemplar e ilustrativo. Mascarenhas et al. (2012), por exemplo, em estudo sobre a construção da agenda em torno da candidatura do Rio de Janeiro à cidade sede dos Jogos Olímpicos e Paralímpicos de 2016, identificam a participação do Estado brasileiro, das organizações esportivas (COI e $\mathrm{COB})$ e do mercado. O estudo conclui, portanto, que o sucesso da candidatura resultou de uma coalizão de força que abrigou um esforço pessoal do expresidente Lula articulado ao projeto de governo, ao modelo de desenvolvimento e à política de reposicionamento do país na geopolítica mundial.

Ancorado, também, numa política conservadora de aproximação e subordinação do Estado brasileiro às entidades proprietárias dos Jogos (COI e $\mathrm{COB}$ ) e, ainda, a um projeto empreendedor orientado para o mercado, segundo os interesses de frações de classe da burguesia, a conquista dos Jogos Olímpicos e Paralímpicos possibilitaram:
[...] reforçar e estabelecer novas relações multilaterais, refletir as conquistas econômicas e políticas a partir de uma plataforma internacional e apresentar o Brasil como referência em liderança na América do Sul. Mais ainda, vencer a eleição para os Jogos Olímpicos e Paralímpicos de 2016 frente a candidatas de países ditos desenvolvidos foi uma forma de se posicionar para uma audiência local e internacional, nas esferas simbólicas e discursivas, como um país que deve ser visto entre os líderes internacionais (ALMEIDA, 2015, p. 263).

É nessa lógica que os países que sediam os megaeventos cumprem o papel de afiançar as condições para o seu desenvolvimento, implicando em ações que vão desde a construção da infraestrutura necessária ao espetáculo esportivo (Estado investidor), bem como na atividade de concessão de créditos a empresas responsáveis pela ampliação da rede hoteleira e serviços na área do turismo, além da construção de arenas esportivas, incremento em tecnologia e informação e outros (Estado financiador) (MASCARENHAS et al. 2012).

Nessa perspectiva, os megaeventos foram incorporados à agenda política nacional, por meio do planejamento estratégico do governo - do qual o Plano Plurianual (PPA) 20122015 (denominado de 'Plano mais Brasil') é uma expressão - bem como do conjunto de ações desenvolvidas no âmbito das políticas esportivas. Nesse plano, por exemplo, o esporte está relacionado aos megaeventos, de maneira que seu objetivo de número 0676 é elucidativo:

Elevar o Brasil à condição de potência esportiva mundialmente reconhecida, com apoio à

Rev. ComCiência - dez. 2018, vol. 3, no. 3, p. 77-89/ doi: 10.36112/issn2595-1890.v3i1.p77-89 
preparação de atletas, equipes e profissionais, da base à excelência esportiva, com estímulo à pesquisa e inovação tecnológica, qualificação da gestão, melhoria e articulação das estruturas, com segurança e confortos nos espetáculos, fomentando a dimensão econômica'.

Por isso, Castellani Filho (2014, p. 100) situa os megaeventos esportivos como artífices de uma lógica de desenvolvimento urbano, ao qual a política esportiva se subordinou:

“[...] de forma consentida - tanto por vê-la conciliada aos interesses do setor conservador (e hegemônico) do campo esportivo brasileiro, quanto pela necessidade de legitimação junto ao campo esportivo [...] - por parte dos responsáveis pela política governamental na referida área".

Assim, é fundamental ter claro, ainda, que os megaeventos esportivos cumprem a função política de procurar espaços geográficos, países e regiões onde o esporte possa gerar formas de reprodução ampliada do capital no tempo e no espaço (OURIQUES, 2014).

Por isso, há uma nova geografia de realização dos megaeventos esportivos pelo mundo. A qual pressupõe abertura de novos mercados para as empresas associadas a entidades do ramo esportivo, sobretudo os fabricantes de materiais esportivos. Essa estratégia tem vínculo com a organização e desenvolvimento capitalista na atualidade que, por isso, inclui os países em desenvolvimento - a fim de carrear novos mercados consumidores.

Há, portanto, um circuito internacional de megaeventos do qual tomam parte as cidades, buscando apresentar-se ao mundo como uma cidade global - uma cidade favorável e amigável aos negócios, um lugar seguro para morar e visitar, para divertir e consumir. O urbanismo olímpico surge com esse propósito - combinando ação estatal e interesses privados, baseandose na monumentalidade arquitetônica, na invenção de lugares e regeneração de espaços de desvalia (MASCARENHAS, 2012).

Nesse sentido, tais eventos contam com a participação política dos Estados nacionais que sediam, da $\mathrm{Fe}$ deração Internacional de Futebol (FIFA) ou do Comitê Olímpico Internacional (COI) como órgãos gestores, da mídia local e internacional e suas interrelações, das empresas privadas nacionais e internacionais, das associações esportivas, dos cidadãos e dos turistas que dele participam.

\section{CONSIDERAÇÕES FINAIS}

$\mathrm{O}$ artigo, por meio de pesquisa bibliográfica e documental, procurou apresentar e analisar os principais fundamentos da política esportiva dos governos do Partido dos Trabalhadores - PT, entre os anos de 2003 a 2016. Para isso, buscou-se problematizar, inicialmente, os elementos mais relevantes e mais pertinentes à contextualização histórica do setor esportivo brasileiro e, na sequência, discutir as principais ações implementadas pelo referido governo na área do esporte brasileiro.

A análise atenta e criteriosa indica o abandono do tom progressista adotado, em 1989, pelo então candidato do PT, Luiz Inácio Lula da Silva, para o campo esportivo brasileiro. Esse tom progressista, expresso na defesa da democratização da cultura esportiva, do conceito positivo de saúde e, também, da participação cidadã e cívica nos megaeventos esportivos cedeu lugar, aos poucos, a uma agenda voltada à inclusão social e formação para a cidadania que, não obstante, foi perdendo espaço e se tornando submissa aos interesses de projetar, internacionalmente, o país no campo do esporte, da economia e da política via promoção e realização de megaeventos.

Essa "virada" na agenda tem relação com as mudanças engendradas no próprio Partido dos Trabalhadores que, para chegar ao governo, formatou alianças políticas afinadas com setores conservadores da burguesia política nacional. Tais transformações tem, também, relação com a reorganização ocorrida no mundo do trabalho fruto da reestruturação produtiva e da precarização das condições de trabalho que fragmentou e fragilizou a base social do partido. Esses elementos representaram obstáculos importantes para a adoção de uma agenda afinada com o rompimento da hegemonia neoliberal. Por isso, pautas de cunho progressista, inclusive no campo do esporte, foram submetidas e/ou relegadas aos determinantes macroeconômicos e à manutenção da governabilidade.

Desse modo, as novas estruturas ministeriais, como é o caso da pasta do Esporte, não conseguiram viabilizar satisfatoriamente preceitos democráticos e de transparência. A submissão e subserviência às entidades de administração e de prática esportiva, fundada no pragmatismo, impediu um debate programático no campo esportivo.

Contudo, os Governos do Partido dos Trabalhadores deram passos importantes como quando chamou o campo esportivo brasileiro, particularmente sua sociedade civil, a pensar, elaborar e/ou construir as diretrizes 
para as políticas do setor. As Conferências Nacionais de Esporte, nessa direção, viabilizaram o debate em torno da democratização das práticas esportivas e do controle social democrático, bem como a incorporação de demandas até então ignoradas pelo Estado brasileiro como era o caso da criação de um Sistema Nacional de Esporte e Lazer - demanda apresentada nas duas primeiras conferências.

Entretanto, o consenso entre o alto rendimento-esporte espetáculo/Estado brasileiro/mercado/entidades de administração e de prática esportiva colonizou o debate da terceira Conferência Nacional de Esporte incorporando, pois, os megaeventos como o princípio organizador da agenda esportiva brasileira. Tal demanda estava inscrita na ambição olímpica de transformar o país numa potência esportiva que traduzisse ao mundo seu desenvolvimento na política e na econômica. Nesses termos, os grandes eventos, pelo seu poder simbólico, econômico e normativo, buscou viabilizar, no Brasil, a reprodução ampliada do capital por meio de uma lógica de desenvolvimento urbano que estava calçada na lógica da cidade global. Aspectos que representaram um recrudescimento de diretrizes e de práticas voltadas à preparação de atletas, de equipes e profissionais, com estímulo à pesquisa e inovação tecnológica, qualificação da gestão, melhoria e articulação das estruturas, com segurança e confortos nos espetáculos, fomentando a dimensão econômica, em detrimento do fomento à cultura esportiva enquanto direito do povo brasileiro.

Pelo apresentado, proceder a um balanço dos sentidos, significados e delineamento das políticas esportivas dos e nos governos do Partido dos Trabalhadores constitui uma tarefa importante e, ao mesmo tempo, complexa, uma vez que implica submeter tais ações à crítica científica, reconhecer entraves, limites e avanços, bem como apreender os múltiplos fatores que são intervenientes nessas mesmas ações.

Apesar das dificuldades, tal empreitada se revela absolutamente necessária, já que implica em possibilidades amplas de reorganização, redirecionamento e implementação de novas ações, programas ou políticas afinadas com o sentido público do esporte, com a noção de direito e de bem sociocultural fundamental à condição dos brasileiros. Por isso, novos estudos precisam ser desenvolvidos, sobremaneira focando nas novas diretrizes legais, os programas e as ações, bem como os dispositivos políticos elaborados nesse período importante da história brasileira.

\section{Referências}

ALMEIDA, B. S. Altius, citius, fortius... ditius? Lógicas e estratégias do Comitê Olímpico Internacional, comitê de candidatura e governo brasileiro na candidatura e escolha dos Jogos Olímpicos e Paralímpicos Rio 2016. Tese (Doutorado em Educação Física Universidade Federa do Paraná), Curitiba, 2015.

ANTUNES, R. A trajetória (e a tragédia) do PT. In: ANTUNES, R. A desertificação neoliberal no Brasil (Collor, FHC e Lula). São Paulo: Autores Associados, 2005.

\section{ATHAYDE, P. F. A. O ornitorrinco} de chuteiras: determinantes da política de esporte do governo Lula e suas implicações sociais. (Tese de Doutorado - Programa de Pós-graduação em
Política Social). Departamento de Serviço Social, Instituto de Ciências Humanas - UnB. Brasília, 2014.

ATHAYDE, P. F.; MASCARENHAS, F.; SALVADOR, E. Primeiras aproximações de uma análise do financiamento da Política Nacional de Esporte e Lazer no Governo Lula. Revista Brasileira de Ciências do Esporte, v. 37, n. 1, jan./mar. 2015.

BEHRING, E. R.; BOSCHETTI, I. Política social no capitalismo: fundamentos e história. 5. ed. São Paulo: Cortez, 2008.

BOITO Jr. A revolução da oportunidade: o esporte no primeiro mandato de Lula, segundo Lula. Rio de Janeiro: Publit, 2005.

BRACHT, V. Sociologia crítica do esporte: uma introdução. 3 ed. Ijuí: Editora Unijuí, 2005.

BRACHT, V.; ALMEIDA, F. Q. Esporte, escola e a tensão que os megaeventos trazem para a Educação Física Escolar. Em Aberto, Brasília, v. 26, n. 89, p. 131-143, jan./jun. 2013.

BRASIL. Lei 8.672 de 06 de julho de 1993 (Lei Zico). Disponível em: <http://www.planalto.gov.br/ccivil_03/ leis/18672.htm>. Acesso em: $10 \mathrm{de}$ setembro de 2014.

Lei 9.615 de 24 de março de

1998 (Lei Pelé). Disponível em:

<http://www.planalto.gov.br/ccivil_03/ leis/19615 consol.htm>. Acesso em: 12 set. 2013.

Decreto $n^{o} .4 .668$ de 09 de

Abril de 2003. Disponível em: <http://www.planalto.gov.br/ccivil_03/ 
decreto/2003/D4668.htm> Acesso em: 15 dez. 2014.

Ministério do Esporte. I Conferência Nacional de Esporte: Esporte, lazer e desenvolvimento humano - documento final. Brasília: ME, 2004.

Ministério do Esporte. III

Conferência Nacional de Esporte: cartilha de orientação. Brasília: ME, 2009.

Plano Plurianual: projeto de lei. Brasília: Ministério do Planejamento, Orçamento e Gestão, 2011.

CASTELAN, L. P. As conferências Nacionais de Esporte na configuração da política esportiva e de lazer no Governo Lula (2003-2010). (Dissertação de Mestrado - Programa de Pósgraduação em Educação Física). Faculdade de Educação Física - Universidade Estadual de Campinas. Campinas, 2011.

CASTELLANI FILHO, L. O estado brasileiro e os direitos sociais: o esporte. In: GARCIA, C. C. et al. (Orgs.). Estado, Política e Emancipação Humana: lazer, educação, esporte e saúde como direitos sociais. Santo André: Apharrabio, 2008.

\section{Educação}

física, esporte e lazer: reflexões nada aleatórias. Campinas: Autores Associados, 2013.

COUTINHO, C. N. O Estado brasileiro: gênese, crise, alternativas. In: LIMA, J. C. F.; NEVES, L. M. W. (Orgs.) Fundamentos da Educação Escolar no Brasil contemporâneo. Rio de Janeiro: Fiocruz/EPS JV, 2006.
FLAUSINO, M. S. Plano Decenal: as políticas públicas de esporte e lazer em jogo. (Dissertação de Mestrado - Programa de Pós-graduação em Educação Física). Faculdade de Educação Física - UnB. Brasília, 2013.

GONÇALVES, M. A. Intercâmbio aproxima países e anuncia 'cultura global'. Folha de São Paulo, São Paulo, 2 nov. Caderno Especial - Globalização, p. 10, 1997.

\section{GONÇALVES, R. Desenvolvimento} às avessas: verdade, má-fé e ilusão no atual modelo brasileiro de desenvolvimento. Rio de Janeiro: LCT, 2013.

LIMA, T. C. S.; MIOTO, R. C. T. Procedimentos metodológicos na construção do conhecimento científico: a pesquisa bibliográfica. Rev. Katál. Florianópolis v. 10 n. esp. p. 37-45, 2007.

LINHARES, M. A. A trajetória política do esporte no Brasil: interesses envolvidos, setores excluídos. (Dissertação de mestrado em Ciência Política - Faculdade de Filosofia e Ciências Humanas UFMG) Belo Horizonte, 1996.

MANHÃES, E. D. Politicas de esportes no Brasil. $2^{\mathrm{a}}$ ed. Rio de Janeiro: Graal, 2002.

MASCARENHAS, F. Megaeventos esportivos e educação física: alerta de tsunami. Movimento, Porto Alegre, v.18, n.1, p. 39-67, jan./mar. 2012.

MASCARENHAS, F. et. al. O bloco olímpico: Estado, organização esportiva e mercado na configuração da agenda Rio 2016. Revista da ALESDE. Curitiba, v. 2. n. 2. p. 15-32, out. 2012.

MATIAS, W. B. O enigma olímpico: o controvertido percurso da agenda e políticas esportivas no Governo Lula. (Dissertação de Mestrado - Programa de Pós-graduação em Educação Física). Faculdade de Educação Física UnB. Brasília, 2013.

MENDES, A.; CODATO, A. The institutional configuration of sport policy in Brazil: organization, evolution and dilemmas. Revista Adm. Pública, Rio de Janeiro, v. 49, n. 03, p. 563-593, maio/jun. 2015.

OURIQUES, N. Megaeventos no Brasil, o desenvolvimento do subdesenvolvimento e o assalto ao Estado. In: CAPELA, P.; TAVARES, E. (Orgs.) Megaeventos esportivos: suas consequências, impactos e legados para a América Latina. Florianópolis: Insular, 2014.

\section{POLÍTICA NACIONAL DE ESPOR-}

TE (Brasil). Brasília: Ministério do Esporte, 2005.

PORTELLI, H. Gramsci e o Bloco Histórico. [Tradução Angelina Peralva]. Rio de Janeiro: Paz e Terra, 1977.

SILVA, L. I. L. Entrevista. Disponível em: Motrivivência, Florianópolis, ano I, jun. 1989.

SILVA, M. R.; SILVEIRA, J.; ÁVILA, A. B. Políticas Públicas para o esporte: cidadania e inclusão social. In: Silva, M. R. (Org.) Esporte, educação, Estado e sociedade: as políticas públicas em foco. Chapecó: Argos, 2007. 
SIMIONATTO, I. Cultura no capitalismo globalizado. Novos consensos e novas subalternidades. In: COUTINHO, C. N.; TEIXEIRA, A. P. Ler Gramsci, entender a realidade. Rio de Janeiro: Civilização Brasileira, 2003.

TAFFAREL, C. N. Z.; SANTOS Jr., C. L. Como iludir o povo com o esporte para o púbico. In: SILVA, M. R. (Org.) Esporte, educação, estado e sociedade: as políticas públicas em foco. Chapecó: Argos, 2007. 